\title{
Domain-specific physical activity and the risk of colorectal cancer: results from the Melbourne Collaborative Cohort Study
}

\author{
Shahid Mahmood ${ }^{1,2^{*}}$ D, Dallas R. English ${ }^{1,2}$, Robert J. Maclnnis ${ }^{1,2}$, Amalia Karahalios ${ }^{1}$, Neville Owen ${ }^{1,3,4,5,6}$,
} Roger L. Milne ${ }^{1,2}$, Graham G. Giles ${ }^{1,2}$ and Brigid M. Lynch ${ }^{1,2}$

\begin{abstract}
Background: Physical activity reduces the risk of colorectal cancer (CRC), but the relevant evidence derives primarily from self-reported recreational and occupational activity. Less is known about the contribution of other domains of physical activity, such as transport and household. We examined associations between domain-specific physical activities and CRC risk within the Melbourne Collaborative Cohort Study.

Methods: Analyses included 23,586 participants who were free from invasive colorectal cancer and had completed the International Physical Activity Questionnaire-Long Form at follow-up 2 (2003-2007). Cox regression, with age as the time metric, was used to estimate hazard ratios (HRs) and 95\% confidence intervals (Cls) for ordinal categories of each physical activity domain.

Results: Adjusted HRs for the highest versus the lowest categories of physical activity were 0.71 ( $95 \%$ Cl: $0.51-0.98$; $p_{\text {trend }}=0.03$ ) for recreational activity; 0.80 (95\% Cl: 0.49-1.28; $p_{\text {trend }}=0.38$ ) for occupational activity; 0.90 (95\% Cl: $0.68-$ 1.19; $p_{\text {trend }}=0.20$ ) for transport activity; and 1.07 (95\% Cl: 0.82-1.40; $p_{\text {trend }}=0.46$ ) for household activity.

Conclusions: Recreational activity was associated with reduced CRC risk. A non-significant, inverse association was observed for occupational activity, whereas no association was found for transport or household domains.
\end{abstract}

Keywords: Survival analysis, Domain-specific physical activity, Exercise, Colon, Hazard ratio

\section{Background}

Systematic reviews conducted by international and national agencies have concluded that there is convincing evidence that physical activity reduces colon, but not rectal cancer risk [1-3]. Recently, a pooled analysis of 1.44 million adults from across the United States and Europe found that higher leisure-time physical activity was associated with a lower risk of both colon (16\% reduction) and rectal (13\% reduction) cancers [4].

Physical activity is a modifiable lifestyle behaviour that can take place in different settings (domains). Physical activity can be influenced by personal attributes such as

\footnotetext{
* Correspondence: mahmoods@student.unimelb.edu.au;

shahidsethi@hotmail.com

${ }^{1}$ Melbourne School of Population and Global Health, University of

Melbourne, 207 Bouverie St, Melbourne, VIC 3010, Australia

${ }^{2}$ Cancer Epidemiology and Intelligence Division, Cancer Council Victoria,

Melbourne, Australia

Full list of author information is available at the end of the article
}

motivation, beliefs, social support from friends and family, as well as the natural and built environment [5]. Correlates of physical activity tend to differ by domains $[6,7]$. For older adults living in high income countries (where colorectal cancer [CRC] is highly prevalent), recreational physical activity comprises only a small part of their total physical activity. Previous studies suggest that the activity energy expenditure of older adults is largely determined by physical activity in occupation and household domains $[6,8]$.

The biological mechanisms underlying the associations between greater physical activity and reduced CRC risk are not clearly understood. Metabolic, inflammatory and hormonal pathways may partially explain how physical activity lowers CRC risk. Low levels of physical activity have been shown to increase blood glucose values and produce insulin resistance and hyperinsulinemia [9]. Insulin may be a key factor in carcinogenesis, due to its

(c) The Author(s). 2018 Open Access This article is distributed under the terms of the Creative Commons Attribution 4.0 International License (http://creativecommons.org/licenses/by/4.0/), which permits unrestricted use, distribution, and reproduction in any medium, provided you give appropriate credit to the original author(s) and the source, provide a link to the Creative Commons license, and indicate if changes were made. The Creative Commons Public Domain Dedication waiver (http://creativecommons.org/publicdomain/zero/1.0/) applies to the data made available in this article, unless otherwise stated. 
mitogenic properties. Insulin has also been described as an essential element for colonic mucosal growth [10, 11]. Increased plasma concentrations of Insulin-like growth factor (IGF) and IGF binding protein-3 provide a favourable environment for cell apoptosis $[12,13]$. Regular exercise has a beneficial effect on inflammatory markers such as adipocytokines [14]. Inflammation is widely acknowledged as a risk factor for numerous chronic diseases, including most cancers [15-17].

Most of the evidence for associations with CRC risk comes from studies that have examined physical activity within recreational and occupational domains. The contribution of activity in other domains, such as transport and household has received less attention [18]. Given that physical activity in different domains varies in terms of its frequency, duration and intensity, it is important to elucidate domain-specific associations with CRC risk.

It is also important to understand the role of domain-specific physical activity in relation to $\mathrm{CRC}$ risk to help tailor health promotion strategies for intervention, and improve policy guidelines for prevention. In this study, we examine prospective associations between domain-specific physical activity, including activity within the recreation, occupation, transport and household domains, and CRC risk for participants in the Melbourne Collaborative Cohort Study (MCCS).

\section{Methods}

\section{Study population}

The MCCS is a prospective cohort study designed to identify relationships between socio-demographic factors, lifestyle patterns, diet and the risk of developing cancer and other non-communicable diseases. A comprehensive description of the MCCS is available elsewhere [19]. In brief, 17,044 men and 24,469 women aged 27 to 76 years (99.2\% were 40 to 69 years) were recruited from the Melbourne metropolitan area between 1990 and 1994 (baseline). Southern European migrants were over-sampled to increase the variability of dietary and other lifestyle factors. Baseline data on physical activity was not domain-specific and did not contain information on duration of physical activity or its intensity. Therefore, we only analysed physical activity data from 27,323 MCCS participants who completed an interviewer-administered questionnaire between 2003 and 2007, which we refer to as follow-up 2. We excluded 3011 participants with prevalent, invasive cancer at follow-up 2, and 726 who did not complete the physical activity section of the interview (see Fig. 1). After these exclusions, 23,586 participants were eligible for analyses related to domain-specific physical activity and CRC risk. For the occupational physical activity domain, we included only the 12,765 participants who were currently working (paid or voluntary). The research protocol was approved by Cancer Council Victoria's Human Research Ethics Committee [20].

\section{Ascertainment of exposure status}

At follow-up 2, a health and lifestyle questionnaire, including a section on physical activity, was administered in person by trained interviewers. The long-form International Physical Activity Questionnaire (IPAQ) was administered to collect data pertaining to domain-specific physical activity. The IPAQ asks about time spent in recreation, occupation, transport and household domains of physical activity. Within each domain, items relating to the frequency, duration and intensity of physical activity were completed. The reference time frame for these questions was the last 3 months, e.g. "In a typical week during the last three months, how many days per week did you do vigorous physical activities in your garden or yard for maintenance?", followed by "how much time did you usually spend doing them in a single day?". Only activities of 10 min' duration or longer were self-reported.

Metabolic equivalents (METs) within each domain were calculated by multiplying hours per week of physical activity by the intensity level assigned by the IPAQ (long form) guidelines for data processing and analysis [21]. As per the IPAQ guidelines, we truncated time spent walking (transport domain) and in recreational physical activity to $180 \mathrm{~min}$ per day for any respondent who reported higher durations, resulting in a maximum of $21 \mathrm{~h}$ per week of activity within each of these two domains. For the domains with more than one intensity level assessed (recreation, household), MET hours per week of moderate and vigorous intensity activities were summed to make a single continuous variable. Total MET hours per week in each domain was then categorised into four exposure levels. For occupational physical activity, in addition to the hours per week of paid or voluntary work, participants were also asked to select their usual occupational activity intensity level from an ordinal scale ('Mainly sitting', 'Mainly sitting with occasional walking and moving about to do tasks', 'Mainly on feet with some light carrying or lifting', or 'Hard physical effort, e.g. scrubbing floors, digging, heavy carrying or lifting'). We used the Compendium of Physical Activities [22], to assign a MET value to the occupational activity intensity level nominated by participants. 'Mainly sitting' was assigned a value of $1.5 \mathrm{METs}$; 'Mainly sitting with occasional walking and moving about to do tasks' was assigned 1.87 METs (assuming 75\% sitting at 1.5 and $25 \%$ on feet at 3.0 METs); 'Mainly on feet with some light carrying or lifting' was assigned a MET value of 3.0, and 'Hard physical effort' was assigned 6.5 METs. A continuous MET hour per week value for occupational physical activity was derived; this was divided into four categories (quartiles). 


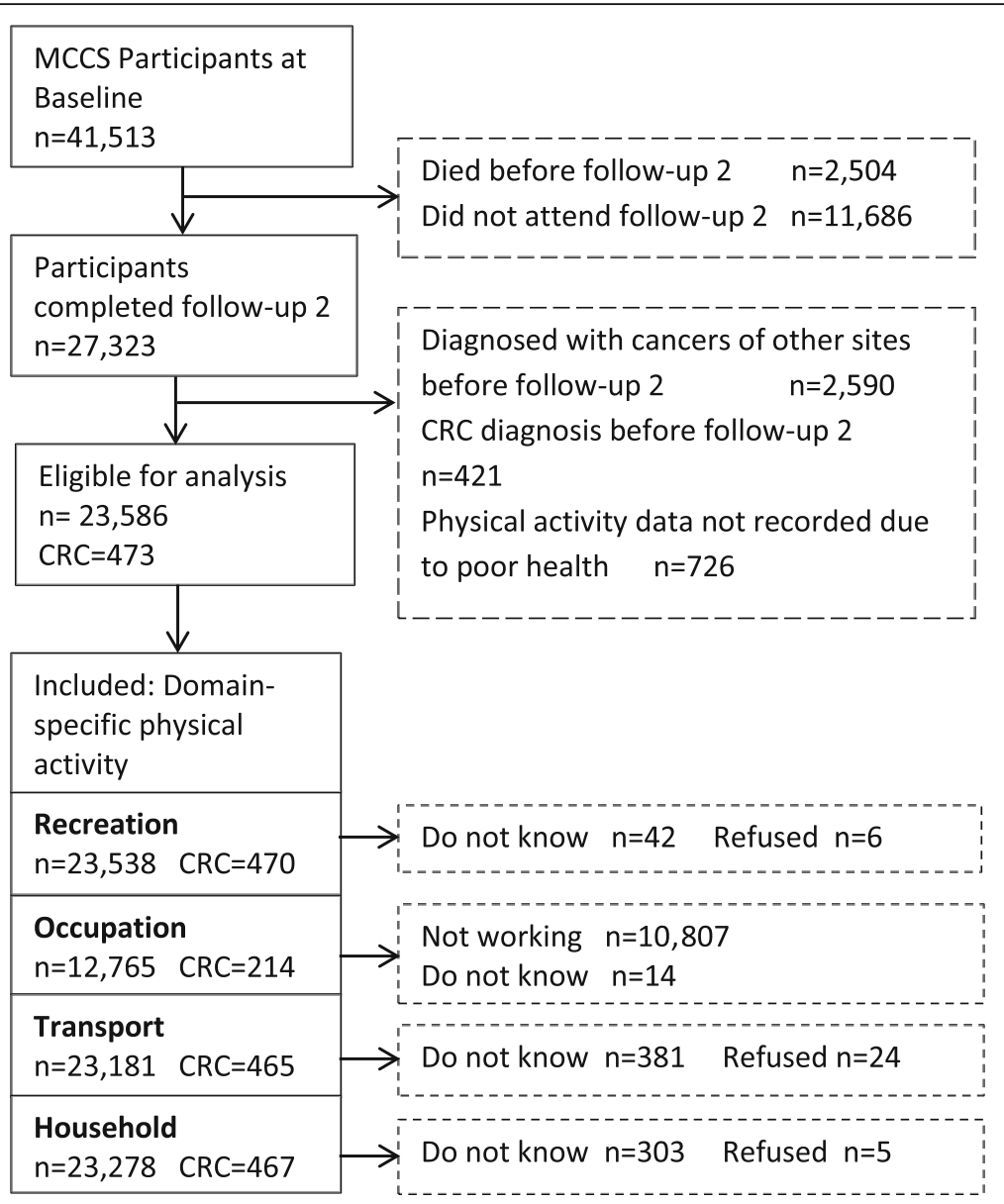

Fig. 1 Flow diagram showing the selection process of Melbourne Collaborative Cohort Study participants for the analyses to examine associations of domain-specific physical activity and colorectal cancer risk

\section{Covariate assessment}

Participants completed a structured interview on socio-demographic characteristics, country of birth, education and lifestyle factors including smoking, alcohol, and diet. Residential postcodes were used to assign participants to a quintile of socio-economic status based on the Index of Relative Socio-Economic Advantage and Disadvantage obtained from Australian Bureau of Statistics census-based Socio-Economic Indexes For Areas (SEIFA). Participants attended the study centre to have anthropometric measurements (body mass index [BMI] calculated from body mass measured using Tanita scales to the nearest $0.1 \mathrm{~kg}$, and height measured by stadiometer to the nearest millimetre/half a centimetre; and waist circumference to nearest millimetre) taken by study staff. Dietary data on red meat (beef, lamb, pork), processed meat (bacon, ham, sausages) and total energy intake (including or excluding fibre) were collected using a self-administered 144-item food and beverages frequency questionnaire (FFQ) designed specifically for MCCS. Frequency questions were complemented by the images of food portion sizes. Nutrient intakes per day from FFQ were calculated using nutrient composition data from NUTTAB 2010 [23]. Alcohol intake data were collected by asking beverage-specific questions for frequency and daily consumption. Similarly, question on smoking comprises of never, ever (time quit) and current (number of cigarettes per day) smoking status.

\section{Follow-up and outcome}

Cancer diagnoses were ascertained by record linkage to the population-based Victorian Cancer Registry (VCR) and to the Australian Cancer Database. The International Classification of Diseases for Oncology, 3rd edition, was used to classify all incident colon (C18.0, C18.2-C18.9), rectosigmoid junction cancers (C19.9) and rectal cancers (C20.9). Ascertainment of cancers was complete to 31 January 2016.

\section{Statistical analyses}

We used Cox proportional hazards regression to estimate hazard ratios (HR) and 95\% confidence intervals 
(CI) for CRC risk in relation to recreation, occupation, transport and household domains of physical activity, using age as the underlying time metric. Follow-up (person-time) for this analysis began at the follow-up 2 interview (when the IPAQ was completed) and ended at the date of CRC diagnosis, death, migration from Australia, or 31 January 2016, whichever came first. Participants who had a CRC tumour with a benign, uncertain or in-situ behaviour codes were censored at date of diagnosis.

Proportional hazards assumptions were checked both graphically and statistically for any violation. Global tests, based on Schoenfeld residuals, showed no evidence of major violation for the physical activity exposure variables, or any of the potential confounders.

We initially considered the following variables as covariates to potentially include in multivariable analyses: age (at follow-up 2 interview), sex, country of birth (Australian/New Zealand/UK; Italy/Greece-recruited at baseline as migrant group from Southern Europe), education (primary, some high/technical, completed high school, completed tertiary degree/diploma), socioeconomic position (quintiles), smoking status (never, former, current), total alcohol consumption in grams per day (none, <10, 10-20, > 20), family history of CRC in first-degree relatives, BMI $\left(\mathrm{kg} / \mathrm{m}^{2}\right)$, waist circumference (centimetres); red meat, processed meat and dietary fibre consumption (all as grams per day) and total energy intake (kilojoules per day).

Three sets of multivariable models were fitted to evaluate the associations of each domain of physical activity with CRC risk. The first model included variables identified by using a directed acyclic graph (DAG, see Additional file 1: Figure S1). This first set of models also considered other potential confounders reported by previous studies, including total energy intake, energyadjusted red meat intake, processed meat and daily dietary fibre consumption. Adding these variables to the models did not materially affect the HRs, and they were not included in our final multivariable models.

Measures of adiposity (BMI or waist circumference) were not included in our primary models because of their potential mediating role (i.e., being in the causal pathway) in the association between physical activity and CRC. However, adiposity might be a confounding factor; the second set of models included waist circumference, which is a stronger predictor of risk of CRC than BMI in this cohort [24]. In the third set of models, missing data were incorporated by multiple imputation using chained equations $[25,26]$. To identify auxiliary variables to include in the imputation model, correlations between each of the covariates with domain-specific physical activity were initially explored to identify strong predictors of missingness to be included in imputation model.
These predictors, together with the exposure and outcome, were included in the imputation model. The imputation process was repeated 20 times to obtain plausible values for the missing data [25].

For each domain of physical activity, the lowest category was used as the reference. Linear trends across physical activity categories were examined by fitting as a continuous variable the median value for all observations in a given category. Departure from linearity was assessed by comparing the models using domain-specific physical activity as categorical and continuous variable and calculating the $p$-value using likelihood ratio test. Statistical interactions were assessed by introducing interaction terms between domain-specific physical activity and sex, country of birth, alcohol, smoking and waist circumference. Likelihood ratio tests were used to assess these interactions.

Sensitivity analyses were conducted by repeating all analyses excluding cases diagnosed in the first 2 years of follow-up. We used 0.05 as the level of statistical significance and all $P$-values were two-sided. All statistical analyses were performed using Stata version 13.0 (Stata Corporation, College Station, Texas, USA).

\section{Results}

Figure 1 shows the flow diagram illustrating the inclusion and exclusion process of MCCS participants for current analyses. A total of 23,586 participants completed the domain-specific physical activity questions and 473 of those were diagnosed with incident colorectal cancers (336 colon, 25 rectosigmoid and 112 rectal).

Table 1 describes the socio-demographic and lifestyle-related characteristics of study participants. CRC cases had a greater mean age than non-cases $(70$ versus 66 years), higher waist circumference $(92.8 \mathrm{~cm}$ versus $90.7 \mathrm{~cm}$ ) and fewer cases had received a tertiary education (25.2\% versus $31.4 \%)$.

Table 2 shows the estimated hazard ratios (HRs) for the associations between physical activity in recreation, occupation, transport and household domains and risk of CRC.

There was a decrease in CRC risk with increasing recreational physical activity $\left(P_{\text {trend }}=0.03\right)$ and the highest quartile ( $>24$ MET hours per week) of recreational physical activity was associated with a $29 \%$ lower risk of CRC (HR $=0.71,95 \%$ CI: 0.51-0.98) (Table 2). This HR estimate was slightly attenuated and became statistically non-significant when waist circumference was included in the model 0.76 (95\% CI: 0.54-1.06, $P_{\text {trend }}=0.07$ ).

The HR estimate for physical activity in the occupation domain indicated an inverse association, but this was not statistically significant (HR $=0.80$; $95 \%$ CI: 0.49 1.28 comparing $>94$ with $\leq 16$ MET hours per week), and there was no evidence of a linear trend with 
Table 1 Socio-demographic and lifestyle characteristics of participants in the Melbourne Collaborative Cohort Study (MCCS- Follow-up 2)

\begin{tabular}{|c|c|c|c|}
\hline & $\begin{array}{l}\text { All participants } \\
(n=23,586)\end{array}$ & $\begin{array}{l}\text { CRC cases } \\
(n=473)\end{array}$ & $\begin{array}{l}\text { Non-cases } \\
(\mathrm{n}=23,113)\end{array}$ \\
\hline $\begin{array}{l}\text { Age at entry (years, } \\
\text { Mean } \pm S D \text { ) }\end{array}$ & $65.6 \pm 8.7$ & $70.2 \pm 8.0$ & $65.5 \pm 8.7$ \\
\hline \multicolumn{4}{|l|}{ Country of birth, n (\%) } \\
\hline Australia/New Zealand/UK & $19,376(82.2)$ & $386(81.6)$ & $\begin{array}{l}18,990 \\
(82.2)\end{array}$ \\
\hline Greece/ltaly & $4210(17.8)$ & $87(18.4)$ & $4123(17.8)$ \\
\hline \multicolumn{4}{|c|}{ Highest education achieved, n (\%) } \\
\hline Primary School & $2976(12.6)$ & $68(14.4)$ & $2908(12.6)$ \\
\hline $\begin{array}{l}\text { Some high/technical } \\
\text { school }\end{array}$ & $8970(38.0)$ & $191(40.4)$ & $8779(38.0)$ \\
\hline Completed high/technical & $4259(18.1)$ & $95(20.1)$ & $4164(18.0)$ \\
\hline Tertiary/diploma/degree & 7381 (31.3) & $119(25.2)$ & $7262(31.4)$ \\
\hline \multicolumn{4}{|l|}{ SEIFA, n (\%) } \\
\hline $\begin{array}{l}\text { Ist Quintile- most } \\
\text { disadvantaged }\end{array}$ & $3701(15.7)$ & $76(16.1)$ & $3625(15.7)$ \\
\hline 2nd Quintile & $4407(18.7)$ & $90(19.0)$ & $4317(18.7)$ \\
\hline 3rd Quintile & $3703(15.7)$ & $71(15.0)$ & $3632(15.7)$ \\
\hline 4th Quintile & $4640(19.7)$ & $104(22.0)$ & $4536(19.6)$ \\
\hline $\begin{array}{l}\text { 5th Quintile - least } \\
\text { disadvantaged }\end{array}$ & $7135(30.3)$ & $132(27.9)$ & $7003(30.3)$ \\
\hline \multicolumn{4}{|l|}{ Smoking status, n (\%) } \\
\hline Never & $14,292(60.6)$ & $270(57.1)$ & $\begin{array}{l}14,022 \\
(60.7)\end{array}$ \\
\hline Former & $8243(34.9)$ & $189(40.0)$ & $8054(34.8)$ \\
\hline Current & $1051(4.5)$ & $14(3.0)$ & $1037(4.5)$ \\
\hline \multicolumn{4}{|c|}{ Current alcohol intake (g/d), n (\%) } \\
\hline None & 7768 (32.9) & $168(35.5)$ & $7600(32.9)$ \\
\hline$<10$ & $6184(26.2)$ & $108(22.8)$ & $6076(26.3)$ \\
\hline $10-20$ & $4283(18.2)$ & $87(18.4)$ & $4196(18.2)$ \\
\hline$>20$ & $5351(22.7)$ & $110(23.3)$ & $5241(22.7)$ \\
\hline \multicolumn{4}{|l|}{ Red Meat intake (g/d), n (\%) } \\
\hline$<30$ & $6097(25.9)$ & $120(25.4)$ & $5977(25.9)$ \\
\hline$\geq 30-<45$ & $5901(25.0)$ & $114(24.1)$ & $5787(25.0)$ \\
\hline$\geq 45-<75$ & $5778(24.5)$ & $109(23.0)$ & $5669(24.5)$ \\
\hline$\geq 75$ & $4628(19.6)$ & $101(21.4)$ & $4527(19.6)$ \\
\hline Missing & $1182(5.0)$ & $29(6.1)$ & $1153(5.0)$ \\
\hline \multicolumn{4}{|c|}{ Processed Meat intake (g/d), n (\%) } \\
\hline$<4$ & $5788(24.5)$ & $97(20.5)$ & $5691(24.6)$ \\
\hline$\geq 4-<8$ & $5461(23.2)$ & $124(26.2)$ & $5337(23.1)$ \\
\hline$\geq 8-<20$ & $6090(25.8)$ & $133(28.1)$ & $5957(25.8)$ \\
\hline$\geq 20$ & $4892(20.7)$ & $87(18.4)$ & $4805(20.8)$ \\
\hline Missing & $1355(5.7)$ & $32(6.8)$ & $1323(5.7)$ \\
\hline
\end{tabular}

Table 1 Socio-demographic and lifestyle characteristics of participants in the Melbourne Collaborative Cohort Study (MCCS- Follow-up 2) (Continued)

\begin{tabular}{llll}
\hline & $\begin{array}{l}\text { All participants } \\
(n=23,586)\end{array}$ & $\begin{array}{l}\text { CRC cases } \\
(n=473)\end{array}$ & $\begin{array}{l}\text { Non-cases } \\
(n=23,113)\end{array}$ \\
\hline Family history of CRC, (\%) & & & \\
$\quad$ No & $20,786(88.1)$ & $412(87.1)$ & $\begin{array}{l}20,374 \\
(88.1)\end{array}$ \\
& $2359(10.0)$ & $50(10.6)$ & $2309(10.0)$ \\
Yes & $441(1.9)$ & $11(2.3)$ & $430(1.9)$ \\
$\quad$ Missing & $90.7 \pm 13.0$ & $92.8 \pm 12.3$ & $90.7 \pm 13.0$ \\
$\begin{array}{l}\text { Waist circumference } \\
\text { (cm, Mean } \pm \text { SD) }\end{array}$ & $27.5 \pm 9.2$ & $26.5 \pm 8.7$ & $27.5 \pm 9.2$ \\
$\begin{array}{l}\text { Dietary fiber intake } \\
\text { (g/d, Mean } \pm \text { SD) }\end{array}$ & $8572 \pm 2267$ & $8531 \pm$ & $8572 \pm$ \\
$\begin{array}{l}\text { Total energy intake } \\
\text { (KJ/d, Mean } \pm \text { SD) }\end{array}$ & & 2292 & 2266 \\
\hline
\end{tabular}

Abbreviations: $M E T$, Metabolic equivalent; $C R C$, Colorectal Cancer; $S D$, standard deviation; KJ, Kilojoules; $m$, meter; $g$, grams; $d$, day; SEIFA, Socio-Economic Indexes For Areas. Values are $\mathrm{n}(\%)$, unless otherwise stated. Percentages are calculated by column

increasing activity $\left(P_{\text {trend }}=0.38\right)$. The associated HR estimates for transport (comparing $>20$ with $\leq 4$ MET hours per week, $\left.\mathrm{HR}=0.90,95 \% \mathrm{CI}: 0.68-1.19 ; \mathrm{P}_{\text {trend }}=0.20\right)$ and household activity (comparing $>36$ with $\leq 7$ MET hours per week, $\mathrm{HR}=1.07,95 \% \mathrm{CI}$ : $\left.0.82-1.40 ; P_{\text {trend }}=0.46\right)$ were weaker and not statistically significant (Table 2).

The HRs did not materially differ between the physical activity domains and CRC risk when applying multiple imputation (Table 2) or when excluding the first 2 years of follow-up (results not shown). There were no statistically significant interactions by sex, country of birth, smoking status, alcohol intake or waist circumference (results not shown).

\section{Discussion}

In this Australian cohort of men and women, higher recreational physical activity was associated with a lower risk of CRC. A statistically non-significant risk reduction was noted for occupational activity, whereas no association was found within the transport or household domains of physical activity.

The strengths of our study include its prospective design, small loss to follow-up (only 96 participants left Australia), use of a physical activity measure that assessed frequency, duration and intensity across various domains, and our use of rigorous statistical methods (including complete-case and multiple imputation analyses to handle the missing data).

These findings should be interpreted in the context of a number of limitations. First, approximately one-third of living MCCS participants did not attend follow-up 2. Second, at follow-up 2, a high proportion of the study sample were retirees and so the occupation domain analyses could only include approximately the $50 \%$ of 
Table 2 Hazard Ratios (95\% Confidence Intervals) for the associations between domain-specific physical activity and colorectal cancer risk, Melbourne Collaborative Cohort Study - Follow-up 2 (2003-2007)

\begin{tabular}{|c|c|c|c|c|c|}
\hline \multirow[t]{2}{*}{ Physical activity domains } & \multirow[t]{2}{*}{ Cases } & \multirow[t]{2}{*}{ Person-years } & \multirow{2}{*}{$\begin{array}{l}\text { Model } 1^{a} \\
\text { HR }(95 \% \text { CI) }\end{array}$} & \multirow{2}{*}{$\begin{array}{l}\text { Model } 2^{b} \\
\text { HR }(95 \% \text { Cl) }\end{array}$} & \multirow{2}{*}{$\begin{array}{l}\text { Model } 3^{c} \\
\text { HR }(95 \% \text { Cl) }\end{array}$} \\
\hline & & & & & \\
\hline \multicolumn{6}{|l|}{ Recreation (MET h/wk) } \\
\hline None & 286 & 132,231 & 1.00 & 1.00 & 1.00 \\
\hline$\leq 8$ & 68 & 38,487 & $0.85(0.65-1.12)$ & $0.86(0.67-1.15)$ & $0.88(0.67-1.14)$ \\
\hline$>8-\leq 24$ & 74 & 43,206 & $0.86(0.66-1.12)$ & $0.84(0.64-1.10)$ & $0.85(0.66-1.11)$ \\
\hline$>24$ & 42 & 29,507 & $0.71(0.51-0.98)$ & $0.76(0.54-1.06)$ & $0.71(0.51-0.98)$ \\
\hline $\mathrm{P}_{\text {trend }} / \mathrm{P}_{\text {departure }}$ & & & $0.03 / 0.68$ & $0.07 / 0.72$ & - \\
\hline \multicolumn{6}{|l|}{ Occupation (MET h/wk) } \\
\hline$\leq 16$ & 87 & 34,181 & 1.00 & 1.00 & 1.00 \\
\hline$>16-\leq 58$ & 52 & 33,301 & $0.84(0.59-1.19)$ & $0.82(0.57-1.76)$ & $0.83(0.58-1.18)$ \\
\hline$>58-\leq 94$ & 38 & 36,076 & $0.79(0.50-1.25)$ & $0.74(0.46-1.18)$ & $0.81(0.52-1.28)$ \\
\hline$>94$ & 37 & 33,660 & $0.80(0.49-1.28)$ & $0.78(0.48-1.26)$ & $0.81(0.51-1.31)$ \\
\hline $\mathrm{P}_{\text {trend }} / \mathrm{P}_{\text {departure }}$ & & & $0.38 / 0.68$ & $0.30 / 0.60$ & - \\
\hline \multicolumn{6}{|l|}{ Transport (MET h/wk) } \\
\hline$\leq 4$ & 117 & 60,099 & 1.00 & 1.00 & 1.00 \\
\hline$>4-\leq 10$ & 135 & 59,997 & $1.15(0.89-1.48)$ & $1.19(0.92-1.54)$ & $1.16(0.91-1.49)$ \\
\hline$>10-\leq 20$ & 115 & 61,682 & $1.00(0.77-1.30)$ & $0.98(0.75-1.29)$ & $1.01(0.78-1.32)$ \\
\hline$>20$ & 98 & 58,173 & $0.90(0.68-1.19)$ & $0.96(0.73-1.28)$ & $0.90(0.69-1.19)$ \\
\hline $\mathrm{P}_{\text {trend }} / \mathrm{P}_{\text {departure }}$ & & & $0.20 / 0.39$ & $0.38 / 0.26$ & - \\
\hline \multicolumn{6}{|l|}{ Household (MET h/wk) } \\
\hline$\leq 7$ & 107 & 60,562 & 1.00 & 1.00 & 1.00 \\
\hline$>7-\leq 18$ & 105 & 63,404 & $0.96(0.73-1.26)$ & $0.94(0.71-1.25)$ & $0.98(0.74-1.27)$ \\
\hline$>18-\leq 36$ & 125 & 58,438 & $1.14(0.87-1.48)$ & $1.15(0.88-1.50)$ & $1.18(0.90-1.53)$ \\
\hline$>36$ & 130 & 58,465 & $1.07(0.82-1.40)$ & $1.06(0.81-1.39)$ & $1.11(0.86-1.45)$ \\
\hline$P_{\text {trend }} / P_{\text {departure }}$ & & & $0.46 / 0.51$ & $0.51 / 0.40$ & - \\
\hline \multicolumn{6}{|c|}{ Recreation and transport combined (Short form IPAQ) } \\
\hline$\leq 6.5$ & 127 & 59,938 & 1.00 & 1.00 & 1.00 \\
\hline$>6.5-\leq 16.5$ & 123 & 59,104 & $1.00(0.79-1.31)$ & $1.01(0.78-1.31)$ & $1.00(0.80-1.25)$ \\
\hline$>16.5-\leq 32.5$ & 119 & 61,982 & $0.95(0.73-1.22)$ & $0.94(0.73-1.23)$ & $0.95(0.74-1.20)$ \\
\hline$>32.5$ & 101 & 62,406 & $0.80(0.61-1.00)$ & $0.83(0.63-1.10)$ & $0.81(0.65-1.01)$ \\
\hline$P_{\text {trend }} / P_{\text {departure }}$ & & & $0.06 / 0.84$ & $0.13 / 0.91$ & - \\
\hline
\end{tabular}

Abbreviations: MET, Metabolic equivalent; $h / w k$, hours per week; SEIFA, Socio-Economic Indexes for Areas

${ }^{a}$ Model 1: Estimates adjusted for age, sex, country of birth, educational status, SEIFA, smoking status, alcohol intake, and mutually adjusted for physical activity domains

${ }^{\mathrm{b}}$ Model 2: Estimates additionally adjusted for waist circumference along with all factors in model 1

'Model 3: Estimates with multiple imputation for missing covariates, adjusted for factors in model 1

participants who were currently working (in either a paid or voluntary capacity). Lastly, physical activity was derived by self-report, which is influenced by social desirability and social approval, which in turn can introduce measurement error, and bias the effect estimates towards the null [27].

The findings for recreational activity in relation to CRC risk are consistent with those reported by previous prospective studies and meta-analyses. In our recent meta-analysis comparing highest versus lowest level of domain-specific physical activity, we observed that recreational physical activity was associated with a $20 \%(\mathrm{RR}=$ $0.80,95 \% \mathrm{CI}: 0.71-0.89)$ and a $13 \%(\mathrm{RR}=0.87,95 \% \mathrm{CI}$ : 0.75-1.01) reduced risk of colon cancer and rectal cancer, respectively [18]. The pooled analysis of 1.44 million adults by Moore et al. [4] reported recreational physical activity to be associated with a decreased risk of colon (90th percentile versus 10th percentile $R R=0.84$, $95 \% \mathrm{CI}: 0.77-0.91)$ and rectal cancer $(\mathrm{RR}=0.87,95 \% \mathrm{CI}$ : $0.80-0.95)$ risk. 
While there was no statistically-significant association with occupational physical activity, the magnitude of the associations by cancer site were similar to our meta-analysis $(\mathrm{RR}=0.74,95 \% \mathrm{CI}$ : $0.67-0.82$ for colon cancer; $\mathrm{RR}=0.88,95 \% \mathrm{CI}: 0.79-0.98$ for rectal cancer) [18], suggesting that increased physical activity in the work place is likely to lower the risk of colorectal cancer and our finding is consistent with existing evidence. There was no significant association between transportrelated physical activity and $\mathrm{CRC}$, but pooled estimates from three studies (Hou et al. [28], Takahashi et al. [29] and Simons et al. [30], in our meta-analysis showed a strong association only for colon cancer ( $R R=0.66$; $95 \%$ CI: 0.45-0.98). The null results for household physical activity are consistent with those of our meta-analysis [18], based on a pooled analysis of studies by White et al. [31], Larsson et al. [32] and Friedenreich et al. [14]. The intensity of occupation, transport and household-related activities undertaken by our participants (mean age 66 years) might not be sufficient to impart a cancer prevention benefit. Alternatively, physical activity undertaken within these domains might be more difficult for participants to recall accurately, or subject to unmeasured confounding.

Measurement of physical activity has long been a difficult issue for epidemiological research. Self-report has been the main method employed by researchers to assess physical activity in most large studies. Self-report is subjective by nature, and estimates obtained by this method are also affected by the way in which questions are framed and asked by interviewers. Although the IPAQ has been validated and is widely used in research, there is considerable inter-individual variability in reporting [5], which may be influenced by age and other participant characteristics [7, 33]. This can result in non-differential measurement error and subsequent risk estimation attenuation. Use of objective methods of physical activity assessment (e.g. accelerometers) may reduce systematic biases and measurement error, but due to cost, data processing complexity and participant burden, many epidemiological studies will continue to use self-report instruments.

Researchers have previously applied regression calibration methods, comparing self-report and accelerometer estimates of physical activity, to derive coefficients to 'correct' relative risks derived from self-reported data. However, it must be noted in this regard that accelerometers are not gold standard measures. Accelerometers are not able to assess domain-specific activity and may not capture certain activities such as upper body movement or load-bearing, resulting in errors in physical activity measurement [34, 35].

Physical activity is a multifaceted exposure as its pattern varies in different behavioural settings across the life course, and it is influenced by the socio-cultural and built environment. Current public health recommendations emphasise moderate-vigorous physical activity. There is, however, an emerging recognition that light-intensity physical activity contributes considerably to overall daily energy expenditure [6], and thus has potential health benefits such as helping prevent the onset of colorectal cancer. Most of the physical activity undertaken by older men and women comprises of tasks within the transport and household domains [8]. The physical activity of older adults may also be influenced by health status, availability of social support, and access to more conducive environments [36]. It is widely reported that recreational activity decreases with advancing age [37]. Women report significantly more time performing household tasks [6], whereas recreational physical activity only constitutes a relatively small part of total daily activity [8]. While our findings suggested that only recreational physical activity was associated with a lower risk of colorectal cancer, with statistically non-significant associations for occupation and transport physical activity domains; we do not think the findings of our single study should undermine the important role that light-intensity activities play in helping older adults to participate in physical activity and maintain physical function. We also cannot disregard the physical activity measurement issues in our study, especially in the household domain, where activities may be difficult to recall reliably, resulting in random misclassification. This type of misclassification may have weakened the associations of physical activity in transport and household domains with decreased colorectal cancer risk. Device-based measurements can improve the validity of recall and improve accuracy and precision of the estimates [38].

\section{Conclusions}

Recreational physical activity was associated with a reduced risk of CRC. There was a non-statistically significant inverse association for occupational physical activity and no association for transport or household physical activity and CRC risk. Physical activity by older adults within these domains may be of insufficient intensity to confer cancer prevention benefits. These findings corroborate the extant evidence that recreational physical activity is inversely associated with CRC risk. The point estimate we observed for occupational activity was of similar magnitude to that reported previously, but our analysis for this domain lacked statistical power.

Due to the scarcity of research conducted to date, further research focusing on physical activity in transport and household domains is warranted to derive a clearer understanding of whether there are CRC prevention benefits to be gained by increasing activity in these contexts. 


\section{Additional file}

Additional file 1: Figure S1. Causal diagram showing the potential confounding variables used in the analysis models. (TIF $2735 \mathrm{~kb}$ )

\section{Abbreviations}

Cl: Confidence interval; CRC: Colorectal cancer; DAG: Directed acyclic graph; FFQ: Food frequency questionnaire; HR: Hazard ratio; IPAQ: Internationa Physical Activity Questionnaire; KJ: Kilo-joules; MCCS: Melbourne Collaborative Cohort Study; METs: Metabolic equivalents; SD: Standard deviation; SEIFA: Socioeconomic indexes for areas; UK: United Kingdom; VCR: Victorian Cancer Registry

\section{Acknowledgements}

We would like to thank all participants of the Melbourne Collaborative Cohort Study, cohort management team and research assistants for their valuable contributions to this study.

\section{Funding}

The MCCS cohort was supported by Australian National Health and Medical Research Council (NHMRC) grants 209057 and 396414 for study design and by Cancer Council Victoria for data collection. Recruitment was funded by VicHealth and Cancer Council Victoria. Cases and their vital status were ascertained through the Victorian Cancer Registry (VCR) and the Australian Institute of Health and Welfare (AlHW), including the National Death Index and the Australian Cancer Database. SM is a recipient of a Melbourne International Fee Remission Scholarship (MIFRS) and a Melbourne International Research Scholarship (MIRS) for his doctorate studies. Lynch is supported by a fellowship from the National Breast Cancer Foundation (ECF-15-012).

The funding bodies had no role in: the design of the study; data collection, analysis, or interpretation; or, in writing the manuscript.

\section{Availability of data and materials}

All data of the study are included in this manuscript. The MCCS dataset is stored in Cancer Council Victoria, Australia. The dataset used in this study contains personal information and are not publicly available, but dataset with de-identified IDs are available from corresponding author on request and when permission from relevant authorities are provided.

\section{Authors' contributions}

SM, BML and DRE: conceived and designed this study. SM, BML, DRE and RJM: developed the methodology. SM, DRE, RJM, GGG, RM: responsible for data acquisition. SM, BML, DRE, RJM: analysed the data supported by NO, RM, GGG, RM and AK. BML, DRE and RJM supervised this study. All authors contributed to interpretation of the data. SM and BML wrote the first drafts of the paper and all authors made essential revisions. All authors read and approved the final manuscript.

\section{Ethics approval and consent to participate}

This study was approved by Cancer Council Victoria's Human Research Ethics Committee. Informed written consent was obtained from participants at recruitment to access clinical records and data for research purposes.

\section{Consent for publication}

Not applicable.

\section{Competing interests}

The authors declare that they have no competing interests.

\section{Publisher's Note}

Springer Nature remains neutral with regard to jurisdictional claims in published maps and institutional affiliations.

\section{Author details}

${ }^{1}$ Melbourne School of Population and Global Health, University of Melbourne, 207 Bouverie St, Melbourne, VIC 3010, Australia. ${ }^{2}$ Cancer Epidemiology and Intelligence Division, Cancer Council Victoria, Melbourne Australia. ${ }^{3}$ Behavioural Epidemiology Laboratory, Baker Heart and Diabetes Institute, Melbourne, Australia. ${ }^{4}$ School of Public Health, The University of Queensland, Brisbane, Australia. ${ }^{5}$ Department of Medicine, Monash
University, Melbourne, Australia. ${ }^{6}$ Swinburne University of Technology, Melbourne, Australia.

Received: 14 March 2018 Accepted: 16 October 2018 Published online: 03 November 2018

\section{References}

1. World Cancer Research Fund International/American Institute for Cancer Research. Continuous update project: diet, nutrition, physical activity and colorectal cancer 2017. Available from: http://wcrf.org/colorectal-cancer-2017.

2. International Agency for Research on Cancer (IARC). New physical activity guidance can help prevent breast, colon cancers. Lyon: France World Health Organization; 2011.

3. Centres for Disease Control and Prevention. Physical activity and health: a report of Surgeon General. Atlanta, GA: U.S. Department of Health and Human Services; 1996

4. Moore SC, Lee I-M, Weiderpass E, Campbell PT, Sampson JN, Kitahara CM, et al. Association of leisure-time physical activity with risk of 26 types of cancer in 1.44 million adults. JAMA Int Med. 2016;176(6):816-25.

5. Bauman AE, Reis RS, Sallis JF, Wells JC, Loos RJ, Martin BW, et al. Correlates of physical activity: why are some people physically active and others not? Lancet. 2012;380(9838):258-71.

6. Csizmadi I, Siou GL, Friedenreich CM, Owen N, Robson PJ. Hours spent and energy expended in physical activity domains: results from the tomorrow project cohort in Alberta, Canada. Int J Behav Nutr Phys Act. 2011;8(1):110.

7. Chrisman M, Nothwehr F, Yang J, Oleson J. Perceived correlates of domainspecific physical activity in rural adults in the Midwest. J Rural Health. 2014; 30(4):352-8

8. Martin KR, Cooper R, Harris TB, Brage S, Hardy R, Kuh D. Patterns of leisuretime physical activity participation in a British birth cohort at early old age PLoS One. 2014:9(6):e98901.

9. Boyle T, Fritschi L, Heyworth J, Bull F. Long-term sedentary work and the risk of subsite-specific colorectal cancer. Am J Epidemiol. 2011;173(10):1183-91.

10. Samad AKA, Taylor RS, Marshall T, Chapman MAS. A meta-analysis of the association of physical activity with reduced risk of colorectal cancer. Color Dis. 2005;7(3):204-13.

11. Lynch B, Leitzmann M. An evaluation of the evidence relating to physical inactivity, sedentary behavior, and cancer incidence and mortality. Curr Epidemiol Rep. 2017:4(3):221-31

12. Haydon AMM, Macinnis RJ, English DR, Morris H, Giles GG. Physical activity, insulin-like growth factor 1, insulin-like growth factor binding protein 3, and survival from colorectal cancer. Gut. 2006:55(5):689-94.

13. Aleksandrova $K$, Boeing $H$, Jenab M, Bueno-de-Mesquita $H B$, Jansen $E$, van Duijnhoven F, et al. Metabolic syndrome and risks of colon and rectal cancer: the European prospective investigation into Cancer and nutrition study (EPIC). Cancer Prev Res. 2011;2011:0218.

14. Friedenreich C, Norat T, Steindorf K, Boutron-Ruault M-C, Pischon T, Mazuir $\mathrm{M}$, et al. Physical activity and risk of colon and rectal cancers: the European prospective investigation into cancer and nutrition. Cancer Epidemiol Biomark Prev. 2006;15(12):2398-407.

15. Coussens LM, Werb Z. Inflammation and cancer. Nature. 2002;420(6917): 860-7.

16. McTiernan A. Mechanisms linking physical activity with cancer. Nature Rev Cancer. 2008:8(3):205.

17. Friedenreich CM, Shaw E, Neilson HK, Brenner DR. Epidemiology and biology of physical activity and cancer recurrence. J Mol Med. 2017:95;1029-42.

18. Mahmood S, Maclnnis R, English D, Karahalios A, Lynch B. Domain-specific physical activity and sedentary behaviour in relation to colon and rectal cancer risk: a systematic review and meta-analysis. Int J Epidemiol. 2017 46(6):1797-813.

19. Milne R, Fletcher A, Maclnnis R, Hodge A, Hopkins A, Bassett J, et al. Cohort profile: the Melbourne collaborative cohort study (health 2020). Int J Epidemiol. 2017:46(6):1757-1757i.

20. Giles G, English D. The Melbourne collaborative cohort study. IARC Sci Publ. 2003:69-70

21. Group I. International physical activity questionnaire(IPAQ). Guidelines for data processing and analysis of the international physical activity questionnaire (IPAQ)-short and long forms. 2006.

22. Ainsworth BE, Haskell WL, Herrmann SD, Meckes N, Bassett DR Jr, TudorLocke C, et al. 2011 compendium of physical activities: a second update of codes and MET values. Med Sci Sports Exerc. 2011;43(8):1575-81. 
23. Bassett JK, English DR, Fahey MT, Forbes AB, Gurrin LC, Simpson JA, et al. Validity and calibration of the FFQ used in the Melbourne collaborative cohort study. Public Health Nutr. 2016;19(13):2357-68.

24. Maclnnis RJ, Hodge AM, Dixon HG, Peeters A, Johnson LE, English DR, et al. Predictors of increased body weight and waist circumference for middleaged adults. Public Health Nutr. 2014;17(05):1087-97.

25. White IR, Royston P, Wood AM. Multiple imputation using chained equations: issues and guidance for practice. Stat Med. 2011;30(4):377-99.

26. Lee KJ, Simpson JA. Introduction to multiple imputation for dealing with missing data. Respirology. 2014;19(2):162-7.

27. Adams SA, Matthews CE, Ebbeling CB, Moore CG, Cunningham JE, Fulton J, et al. The effect of social desirability and social approval on self-reports of physical activity. Am J Epidemiol. 2005;161(4):389-98

28. Hou L, Ji B-T, Blair A, Dai Q, Gao Y-T, Chow W-H. Commuting physical activity and risk of colon cancer in Shanghai. China Am J Epidemiol. 2004; 160(9):860-7.

29. Takahashi H, Kuriyama S, Tsubono Y, Nakaya N, Fujita K, Nishino Y, et al. Time spent walking and risk of colorectal cancer in Japan: the Miyagi cohort study. Eur J Cancer Prev. 2007;16(5):403-8.

30. Simons CC, Hughes LA, Van Engeland M, Goldbohm RA, Van Den Brandt PA, Weijenberg MP. Physical activity, occupational sitting time, and colorectal cancer risk in the Netherlands cohort study. Am J Epidemiol. 2013;177(6):514-30.

31. White E, Jacobs EJ, Daling JR. Physical activity in relation to colon cancer in middle-aged men and women. Am J Epidemiol. 1996;144(1):42-50.

32. Larsson S, Rutegård J, Bergkvist L, Wolk A. Physical activity, obesity, and risk of colon and rectal cancer in a cohort of Swedish men. Eur J Cancer. 2006; 42(15):2590-7.

33. Du H, Li L, Whitlock G, Bennett D, Guo Y, Bian Z, et al. Patterns and sociodemographic correlates of domain-specific physical activities and their associations with adiposity in the China Kadoorie biobank study. BMC Public Health. 2014;14(1):826.

34. Lim S, Wyker B, Bartley K, Eisenhower D. Measurement error of self-reported physical activity levels in new York City: assessment and correction. Am J Epidemiol. 2015;181(9):648-55.

35. Arem H, Keadle SK, Matthews CE. Invited commentary: meta-physical activity and the search for the truth. Am J Epidemiol. 2015;181(9):656-8.

36. Sparling PB, Howard BJ, Dunstan DW, Owen N. Recommendations for physical activity in older adults. BMJ. 2015;350:h100.

37. Ramires W, Wehrmeister FC, Böhm AW, Galliano L, Ekelund U, Brage S, et al. Physical activity levels objectively measured among older adults: a population-based study in a southern city of Brazil. Int I Behav Nutr Phys Act. 2017;14(1):13.

38. Celis Morales C, Perez Bravo F, Ibañez L, Salas C, Bailey MES, Gill JMR, et al. Objective vs. self-reported physical activity and sedentary time: effects of measurement method on relationships with risk biomarkers. PLoS One. 2012; $7(5): e 36345$

Ready to submit your research? Choose BMC and benefit from:

- fast, convenient online submission

- thorough peer review by experienced researchers in your field

- rapid publication on acceptance

- support for research data, including large and complex data types

- gold Open Access which fosters wider collaboration and increased citations

- maximum visibility for your research: over $100 \mathrm{M}$ website views per year

At BMC, research is always in progress.

Learn more biomedcentral.com/submissions 